THIAGO BARBOSA WANDERLEY

\title{
A INTERPRETAÇÃO DAS NORMAS TRIBUTÁRIAS E OS LIMITES PARA A ALTERAÇÃO DE CONCEITOS DE DIREITO PRIVADO
}

\author{
Dissertação de Mestrado \\ Orientador: Professor Emérito Dr. Paulo de Barros Carvalho
}

UNIVERSIDADE DE SÃO PAULO

FACULDADE DE DIREITO

São Paulo - SP

2017 


\title{
A INTERPRETAÇÃO DAS NORMAS TRIBUTÁRIAS E OS LIMITES PARA A ALTERAÇÃO DE CONCEITOS DE DIREITO PRIVADO
}

\author{
Dissertação de Mestrado apresentada à Banca \\ Examinadora do Programa de Pós-Graduação em \\ Direito da Faculdade de Direito da Universidade de São \\ Paulo, como exigência para obtenção do título de \\ Mestre em Direito, na área de concentração do Direito \\ Econômico, Financeiro e Tributário, sob a orientação \\ do Professor Emérito Dr. Paulo de Barros Carvalho.
}

UNIVERSIDADE DE SÃO PAULO

FACULDADE DE DIREITO

São Paulo - SP 


\section{Banca Examinadora:}

Orientador: Professor Emérito Dr. Paulo de Barros Carvalho Instituição: Faculdade de Direito da USP Assinatura:

Professor:

Instituição: Assinatura:

Professor:

Instituição: Assinatura:

Professor:

Instituição: Assinatura: 


\section{Wanderley, Thiago Barbosa}

A INTERPRETAÇÃO DAS NORMAS TRIBUTÁRIAS E OS LIMITES PARA ALTERAÇÃO DE CONCEITOS DE DIREITO PRIVADO / Thiago Barbosa Wanderley ; orientador Paulo de Barros Carvalho -- São Paulo, 2017.

181

Dissertação (Mestrado - Programa de Pós-Graduação em Direito Direito Econổmico, Financeiro e Tributário) Faculdade de Direito, Universidade de São Paulo, 2017.

1. Direito Tributário. 2. Intertextualidade. 3. Direito de sobreposiçăo. 4. Conceitos e definiçōes. 5. norma tributária. I. Carvalho, Paulo de Barros, orient. II. Título. 


\section{AGRADECIMENTOS}

Agradeço primeiramente ao meu orientador, Professor Paulo de Barros Carvalho, pela honra de me conceder seu tempo e compartilhar sua inigualável sabedoria amealhada durante uma carreira impecável. Desde meu primeiro contato com sua teoria, nas cadeiras do Instituto Brasileiro de Estudos Tributários - IBET no ano de 2008, suas lições têm guiado minha vida acadêmica e profissional.

À minha mulher, Elza Lira, agradeço por todo o carinho e apoio concedido desde quando o ingresso no mestrado da Universidade de São Paulo era apenas um sonho distante. Sem você essa conquista não teria o mesmo valor, muito obrigado!

À todos os Professores com quem tive a honra de aprender valiosas lições nas inspiradoras instalações da Faculdade de Direito da USP: Paulo Ayres Barreto, Luís Eduardo Schoueri, Gerd Willi Rothmann, Maria Rita Ferragut, Fabiana del Padre Tomé e Rosana Oleinik.

Aos colegas que investiram seu tempo em instigantes e prazerosas discussões, cujas ideias certamente contribuíram ao desenvolvimento do texto: Luciano Ogawa, Cristiane Pires, Rafael Romero, Caio Takano, Fábio Silva, André Berçot, Carlos Crossara, Bruno F e José Luiz Crivelli.

Aos meus grandes amigos Rodrigo Griz, Lucas Galvão e Rodrigo Borges, cuja sincera torcida em todos os momentos me impulsionou até a entrega da versão final.

Por fim, agradeço ainda a todos os familiares e amigos que transmitiram muito energia positiva para que este projeto se concretizasse. 


\section{RESUMO}

Esta pesquisa tem por objetivo analisar se existem e quais são os limites estabelecidos para que uma norma tributária realize a alteração de conceitos de direito privado utilizados em sua composição. Traçamos as linhas gerais sobre a atividade de conceituação e da interpretação, nos filiando ao estabelecido pela Hermenêutica Filosófica, segundo a qual o intérprete possui papel fundamental na construção dos sentidos. A unidade do sistema é tomada por premissa para averiguar se tal unidade implica a necessidade do direito tributário acolher os conceitos firmados pelo direito privado sem qualquer possibilidade de alteração. Embora o direito tributário seja considerado um direito de sobreposição, não existe qualquer primazia do direito privado sobre o tributário, sendo necessário apenas, na construção das normas tributárias, ater-se aos conceitos privados utilizados pela Constituição para delimitação de competência tributária.

Palavras-chave: conceito; definição; sistema jurídico; interpretação; dialogismo; intertextualidade; Hermenêutica Filosófica; direito de sobreposição; efeitos tributários. 


\begin{abstract}
This research aims to discover if there are and what are the limits established in a way that tax legislation may alter concepts of private law. An overview was given concerning the conceptualization and the interpretation involved according to the rules of hermeneutics. This philosophical theory states that the interpreter has a fundamental role in the construction of senses. The system unit is under investigation with the purpose of obtaining information about a possible adoption of Private Law concepts by Tax Law without any change in its meaning. Even though Tax Law is considered a subsidiary/overlapping right, there's no supremacy of Private Law over Tax Law. Nonetheless, it's important that legal practitioners draw their attention to the Private Law concepts found in the Constitution in order to define the competence on taxation.
\end{abstract}

Keywords: concepts, definition, legal system, interpretation, dialogism, intertextuality, philosophical hermeneutics, overlapping rights, taxation effects. 


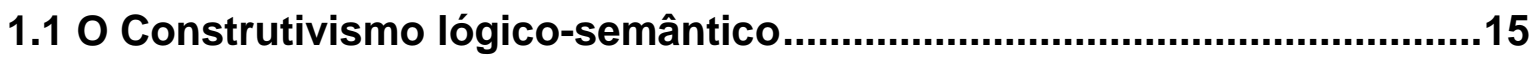

1.2 Direito Positivo e Ciência do Direito ..........................................................19

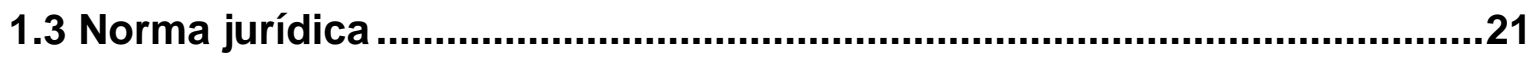

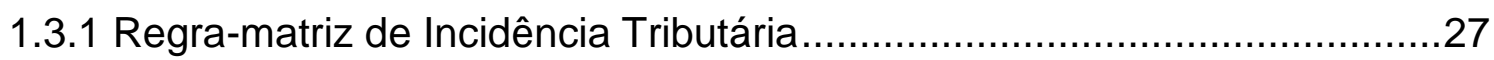

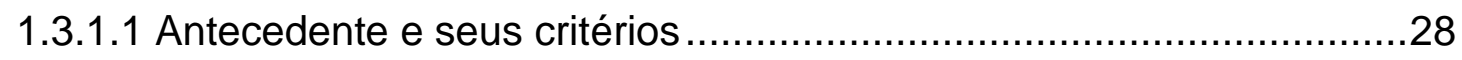

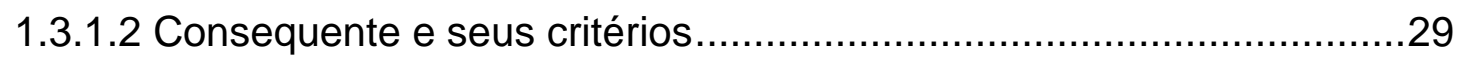

1.4 Conceituar, definir e classificar ...................................................................

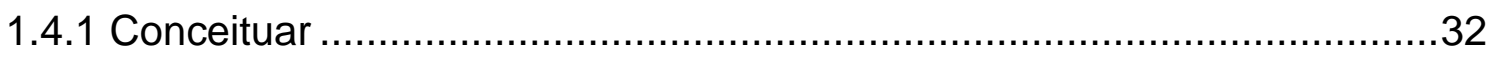

1.4.2 Conotação e Denotação .................................................................34

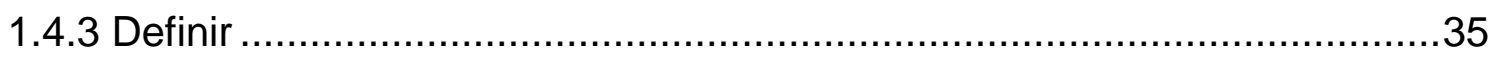

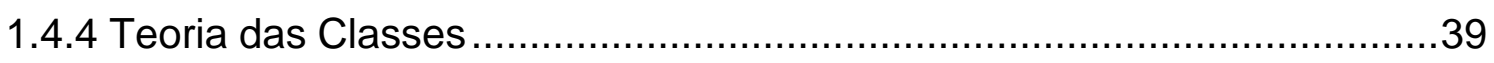

1.4.5 Legislador e aplicador do direito como operador de conceitos e classes .42

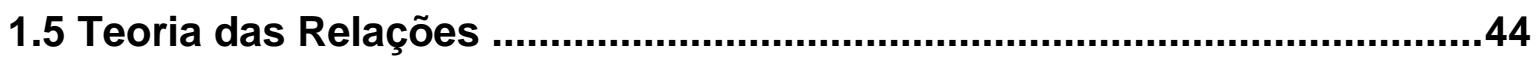

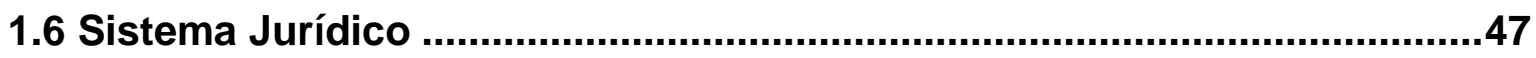

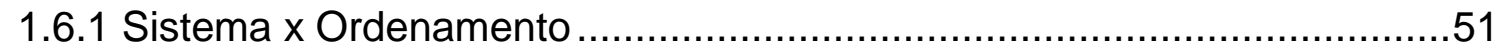

1.6.2 A relação entre o sistema do direito positivo e o sistema social ...............52

1.6.3 A unicidade do sistema jurídico e sua divisão em ramos .........................54

CAPÍTULO 2 - INTERPRETAÇÃO DO DIREITO ….......................................57

2.1 O CÍRCULO DE VIENA E O NASCIMENTO DA FILOSOFIA DA

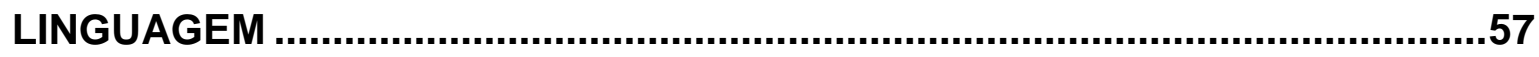

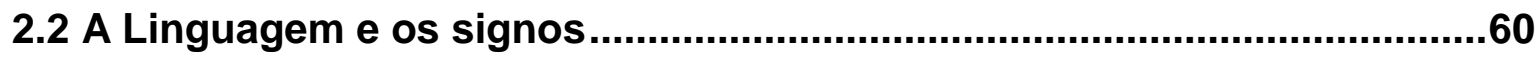

2.2.1 Análise semiótica do Direito ....................................................63 
2.3 Hermenêutica Tradicional x Hermenêutica Filosófica .66

2.3.1 Inesgotabilidade da interpretação (limitada ao sentido possível) .67

2.3.2 Intertextualidade

2.3.3 Paradoxo da interdisciplinaridade. 72

2.4 Os métodos de interpretação 76

2.50 percurso gerador de sentido dos textos jurídicos 79

2.6 Relação entre os valores e a interpretação 83

CAPÍTULO 3 - DIALOGISMO ENTRE OS TEXTOS DE DIREITO TRIBUTÁRIO E DIREITO CIVIL

3.1 O início do embate entre a autonomia do direito tributário e o Primado do Direito Civil .86

3.2 Origens da Teoria da Consideração Econômica no direito tributário .91

3.3 A norma do art. 109 do CTN e a classificação do direito tributário como direito de sobreposição 100

3.3.1 A confirmação da sobreposição por meio do art. 116 do CTN 107

3.3.2 O que significa "definir os efeitos tributários". 111

3.4 Limitações à modificação de conceitos de direito privado - art. 110 do CTN.

3.4.1 Construção dos conceitos constitucionais

3.4.2 Interpretação dinâmica ou estática dos conceitos de direito privado utilizados na Constituição para definir competências

3.5 Modificação de um conceito de direito privado não utilizado para definir competência possui efeito imediato para fins tributários? .123

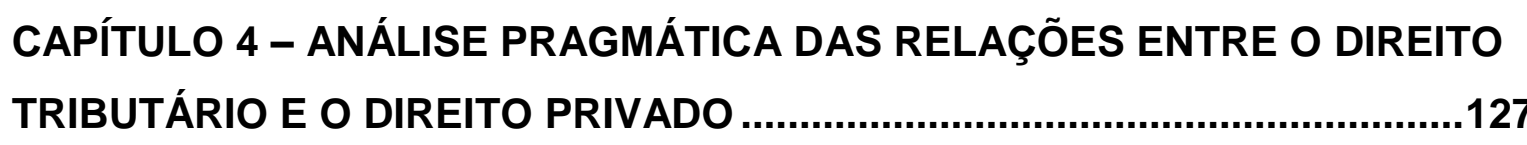

4.1 O Conceito de "serviço" para fins de incidência do ISS 127 
4.2 O conceito de "mercadoria" para incidência do ICMS

4.2.1 Incidência do ICMS sobre softwares

4.3 O conceito de propriedade para fins de IPVA

4.3.1 Impossibilidade de instituição do IPVA sobre a posse de veículo automotor?

4.4 Conceito de Receita e Faturamento no âmbito do PIS e COFINS

4.5 O Conceito civil de "prédio" e sua repercussão nos créditos de PIS e COFINS

CONCLUSÃO 


\section{INTRODUÇÃO}

As múltiplas relações travadas no seio da sociedade organizada constituem o objeto do Direito, estipulando as "regras do jogo" em que figuram diversos personagens (Estado, particulares, empresas etc.) que travam relações entre si tendo por objeto itens passíveis de negociação (bens móveis, imóveis, empréstimo monetários, entre outros). As avenças, que num passado remoto foram entabuladas à margem do poder do Estado, hoje são exclusivamente firmadas sob sua tutela, devendo ser obedecidas as normas jurídicas que conferem validade e legitimidade às negociações.

Com o ingresso do Estado na ingerência dos negócios firmados entre os particulares, uma parcela da riqueza produzida passou a ser recolhida como forma de financiar os gastos públicos e fornecer os serviços básicos disponibilizados ao cidadão, criando-se então o tributo, representando a parte da riqueza adjudicada pelo Estado por escolha dos próprios particulares, já que estes anuíram à expropriação quando da aprovação das leis que representam sua vontade.

A crescente multiplicidade de negócios jurídicos demandou uma complexa regulamentação dos mesmos por normas de direito privado, as quais conceituam institutos e formas sem as quais as avenças não adquirem validade. Dado que o direito tributário surgiu em momento posterior às estipulações do direito privado, a pena do legislador tributário passou a fazer referência a diversos institutos firmados privatisticamente, elegendo-os como elemento de composição da norma tributária, o que só aumentou a complexidade do sistema jurídico.

Dessa forma, o presente trabalho tem como objetivo analisar o direito tributário enquanto ramo inserido no sistema do Direito, sistema esse que possui por principal característica ser uno e indivisível, distribuindo-se as normas jurídicas em diferentes ramos apenas como corte epistemológico que visa a diminuir a complexidade de seu estudo. Da referida divisão em ramos, pretendemos orientar nossos esforços para verificar a construção das normas tributárias e o método de interpretação utilizado para tanto, analisando como 
aquelas podem dialogar com normas do direito privado e delineando quais os limites que o direito tributário possui para apropriar-se e manusear os conceitos que deitam raízes no direito privado.

Dito por outros torneios, o cerne do trabalho proposto é discutir qual o limite conferido ao legislador tributário para realizar modificações nos conceitos cunhados originalmente no direito privado, fazendo-o com base no ordenamento jurídico brasileiro, o que implica obediência à Constituição Federal e aos artigos 109 e 110 do Código Tributário Nacional.

Para que tal propósito seja atingido com a cientificidade que uma dissertação de mestrado exige, trazemos no primeiro capítulo os conceitos básicos que sustentam a investigação, elegendo o Construtivismo LógicoSemântico como método de investigação. Trazemos ainda as notas elementares sobre a própria atividade de conceituar e definir, demonstrando que os conceitos jurídicos gravitam dentro de um sistema uno (composto unicamente por normas jurídicas), mas que essa unidade não necessariamente nos remete a uma unidade conceitual dentro do sistema.

No segundo capítulo, abordaremos o processo de interpretação do Direito no intuito de demonstrar a utilidade dos recursos semióticos para a construção do sentido do texto, realizando uma análise sintática, semântica e pragmática dos conceitos crivados no sistema. Nesse ponto, torna-se primordial firmar o papel decisivo conferido ao intérprete para a construção do sentido, indicando nossa filiação aos ditames da Hermenêutica Filosófica. Embora o processo de interpretação seja inesgotável, procuraremos nos pautar sempre no sentido possível das palavras, tal como estabelecido dentro do discurso jurídico brasileiro, demonstrando que tal discurso é composto por um emaranhado de textos que se interpelam para a construção de um sentido. Nosso corte epistemológico nos permite pinçar apenas os textos normativos de direito privado que estabelecem institutos, conceitos e formas utilizadas pela legislação tributária para fins de instituição de suas exações, voltando nossa atenção sobre a possibilidade de a lei tributária promover alterações nesses conceitos. 
Fornecido o instrumental teórico necessário, discorreremos no terceiro capítulo sobre a intertextualidade entre o direito privado e o direito tributário. Afinal, o legislador tributário, ao mencionar um conceito de direito privado, está enclausurado em seu sentido original? Existe uma margem para realizar alterações em tais conceitos? Caso existente, quais os limites para a realização de tal transformação conceitual?

Para responder a essas indagações que tocam o ponto nodal do presente trabalho, consideraremos que a complexidade do sistema permite uma divergência conceitual entre os ramos privado e o tributário (dentro de certos limites). Em sua gênese, os doutrinadores se dividiram entre a defesa de um Primado do Direito Privado e a Autonomia do Direito Tributário, embate que tomou substância no início do século passado, incrementado pela teoria da consideração econômica, que pretendia abrir as fronteiras do Direito aos outros sistemas para perquirir a substância econômica aprisionada pela norma tributária. Referida discussão foi travada em momento anterior à elaboração do Código Tributário Nacional e trouxe como principais marcas os enunciados dispostos nos arts. 109 e 110, os quais denotam a estreita ligação entre o direito tributário e o direito privado. Todavia a referida ligação é analisada pela doutrina de diferentes formas, ora atribuindo um papel secundário ao direito tributário, ora firmando a liberdade do legislador para desvincular-se do direito privado. Abordaremos o sentido das referidas normas jurídicas no intuito de delimitar a esfera de autonomia atribuída ao legislador em matéria tributária.

Uma vez estabelecidos os limites delineados pelos art. 109 e 110 ao legislador em matéria tributária, traremos no quarto capítulo uma análise pragmática de alguns casos que demonstram o exercício (ou não) da liberdade conferida, expondo hipóteses concretas em que o legislador e o aplicador da lei decidiram por fazer uma remissão pura ao conceito de direito privado ou pugnaram por alterá-lo.

Por fim, cabe-nos fazer uma importante ressalva. Embora doutrinadores renomados tenham recentemente voltado sua atenção à matéria de planejamento tributário, abordando de forma proficiente a possibilidade de a autoridade administrativa desconsiderar os negócios jurídicos firmados pelos particulares 
(com espeque no parágrafo único do art. 116 do CTN), não voltaremos nossa atenção para essa problemática. Ao revés, pretendemos atuar numa etapa anterior à desconsideração promovida pela autoridade fiscal, contribuindo para o planejamento ao fornecer um alicerce acerca da delimitação dos poderes conceituais atribuídos ao legislador em matéria tributária para alterar conceitos firmados anteriormente pelo direito privado. 


\section{CONCLUSÃO}

Dentro do amplo espectro da realidade social (sistema social), o direito positivo é entendido como o conjunto de normas jurídicas válidas em determinado território, o qual tem por objetivo regular as condutas intersubjetivas travadas no seio dessa sociedade.

As normas são ordens emanadas com o intuito de direcionar as ações dos indivíduos e, para que sejam classificadas como jurídicas, deverão ser proferidas por uma autoridade competente, seguindo o procedimento previsto em diploma legislativo. Referidas normas constituem comandos que designam quais comportamentos são permitidos, obrigatórios e proibidos, construídos sob uma forma hipotético-condicional segundo a qual, se ocorrer a situação prevista na regra, deve-ser a ocorrência de uma consequência firmada pela norma.

De modo a facilitar a análise e compreensão das normas jurídicas na seara tributária (enquanto significação hipotético-condicional), foi criada uma estrutura sintática denominada regra-matriz de incidência tributária (RMIT). Segundo essa regra, a hipótese (ou antecedente normativo) da norma é dividida entre um critério material (composto por um verbo e complemento que indica qual a ação humana objeto da norma), um critério espacial (determina onde a conduta regulada é tido por ocorrida) e um critério temporal (estipula o momento no qual a conduta reputa-se juridicamente existente). Uma vez vislumbrada a ocorrência dos elementos do antecedente, instaura-se a relação jurídica prevista no consequente normativo, o qual é formado pelo critério subjetivo (composto pelos sujeitos ativo e passivo que comporão a relação jurídica) e o critério quantitativo (apontando a base de cálculo que servirá para mensurar a materialidade, bem como a alíquota que corresponderá ao percentual a ser repassado ao Estado a título de tributo).

Para estabelecer quais as condutas intersubjetivas reguladas pelo Direito, - legislador se serve essencialmente dos textos legais para transmitir sua mensagem. Todavia, todo texto não passa de um conjunto de símbolos cuja atribuição de sentidos é conferida pelo intérprete que domina aquela língua, ou 
seja, que tem conhecimento das convenções utilizadas pelos usuários daquele idioma.

Dominando o português, ao travarmos contato com um texto (jurídico ou não), a ideia que os termos provocam em nossa mente corresponde à noção de conceito. Dessa forma, ao lermos o vocábulo cadeira, nos vem à mente uma ideia de um objeto utilizado para que o indivíduo se sente. Por outro lado, a definição consiste em pôr em palavras um determinado conceito, ou seja, explicá-lo por meio de outros termos.

Nesse ponto, é importante frisar que não há uma relação ontológica entre o termo e o objeto que ele representa. Referida relação é realizada por meio de um arbitramento firmado pelos utentes da linguagem, que por sua vez firmam tal relação por meio de outros termos, razão pela qual nunca conceituamos os objetos em si, mas sim os termos que utilizamos para se referir ao objeto.

Assim, quando utilizados dentro de uma determinada comunidade linguística, os termos passam a transmitir certos conceitos e, para que o interlocutor compreenda a mensagem, podemos informar as características estabelecidas para que os objetos pertençam a determinado conceito (conotação) ou simplesmente elencar quais os objetos específicos que se enquadram em tal conceito (denotação).

Ao elucidar a ideia conceitual por meio das definições, acabamos por segregar do todo aqueles objetos que atendem às suas notas conotativas, classificando-os como pertencentes àquele determinado conceito, em detrimento de todo o resto, que não poderá ser classificado como correspondente à ideia (conceito) do termo em análise. Dessa forma, o ato de classificar (distribuir em classes) corresponde à verificação da extensão do significado do termo, criandose um conjunto.

Trazendo as noções de conceituação e definição ao mundo jurídico, temos que o legislador seleciona entre os comportamentos sociais aqueles que reputa relevante, trazendo-os ao mundo jurídico por meio das normas jurídicas. Por sua vez, as normas jurídicas têm como ponto de partida o texto legal, os quais exprimem suas mensagens por meio de conceitos e definições firmadas nos 
diplomas legais. Passamos então a travar contato com termos como serviço, mercadoria, propriedade, faturamento, entre outros, e para conhecer o sentido de tais termos precisamos recorrer às definições constantes na legislação de regência.

Inicia-se então a empreitada em busca da construção de conceitos por meio da análise das normas jurídicas. Referidas normas encontram-se imersas no sistema jurídico, o qual pode ser definido como conjunto de todos os enunciados prescritivos que visam regular as condutas humanas. Nota-se que o sistema é composto unicamente por normas jurídicas, as quais não possuem distinção entre si, razão pela qual se conclui que o sistema jurídico é uno e indecomponível.

Como o conjunto de diplomas legais é excessivamente numeroso, os estudiosos realizaram um corte epistemológico, dividindo o Direito em ramos tãosomente para fins didáticos, facilitando a aproximação e compreensão das normas. Entre os variados critérios de classificação, às normas que regulamentam as relações travadas entre os particulares foi reservado o ramo do direito privado, enquanto as normas na qual o Estado figura como parte soberana foram aglutinadas no ramo do direito público (dentro do qual se encontram o ramo do direito tributário, no qual o Estado exerce figura como uma das partes ao exercer seu poder de instituir tributos).

No entanto, não se pode perder de vista que o sistema jurídico é demasiadamente complexo, razão pela qual sua unidade não implica uma unicidade conceitual. Dito por outros torneios, é preciso asseverar que teremos conceitos firmados no seio do sistema que, mediante a análise de um diferente contexto normativo, poderão ser restringidos ou ampliados, sempre tomando como base as próprias normas jurídicas.

Após o movimento conhecido como Círculo de Viena, surgido no início do século $\mathrm{XX}$, a linguagem passou a tomar o papel central das investigações científicas, deixando de ser entendida como mera representação da realidade para ostentar o predicado de criadora da própria realidade.

Nesse contexto desenvolveu-se a denominada Hermenêutica Filosófica, segundo a qual o intérprete construirá o sentido do texto, assumindo 
posicionamento preponderante no processo interpretativo, posto que, ao revés do que pregava a Hermenêutica Tradicional, não há mais que se falar sobre a existência de um conteúdo aprisionado no próprio texto, que deveria ser descoberto pelo intérprete.

A construção do sentido do texto pelo intérprete foi devidamente estruturada pela Semiótica como uma relação triádica formada entre o suporte físico (suporte material que concretiza a mensagem), o significado (objeto do mundo ao qual o signo se refere) e a significação (ideia conceitual formada na mente do intérprete).

Embora os sentidos sejam construídos pelo intérprete, possibilitando infindáveis interpretações, isso não significa a admissão de uma anarquia de significações, uma vez que o processo de construção do sentido deve ter sempre o sentido possível das palavras como ponto de partida.

Assim, constatamos que os textos não possuem "vida própria" necessitando do intérprete para adjudicar-lhes sentido. Ademais, como os textos sempre tomam (em alguma dimensão) parâmetros conceituais constituídos por diversos outros textos, existe um verdadeiro diálogo entre tais textos, que é denominado intertextualidade (ou dialogismo).

Optamos por investigar a intertextualidade firmada entre os textos jurídicos, com especial atenção àquela firmada entre os textos do direito privado e do direito tributário. Isso porque, ao firmar um imposto sobre a propriedade de um veículo automotor (por exemplo), a norma tributária nos remete à legislação de direito privado que nos traz o conceito de propriedade.

Como afirmamos linhas atrás, o sistema jurídico é um amálgama complexo, e a correta compreensão das normas exige que o intérprete analise o contexto no qual estão inseridas, cotejando os princípios informadores da relação jurídica sob enfoque. No início do século passado, no seio do debate acerca da sistematização do sistema jurídico, o professor francês Louis Trotabas passou a defender uma autonomia do direito tributário, enquanto seu opositor, também catedrático da Universidade de Nancy (França), defendia a primazia do direito privado. 
Do embate entre os aludidos professores resultou a superação do Primado do Direito Privado, restando sedimentado que as particularidades conferidas ao ramo tributário conferiam uma certa autonomia ao ramo, tomando-se o vocábulo da autonomia não em seu sentido restrito, mas naquele adotado por Trotabas em seu Ensaio, ou seja, de que esse ramo possui particularidades que implicam a necessária observância de seus institutos e princípios informadores. A rigor, podemos afirmar que foi firmada a igualdade entre todos os ramos, e que os termos poderão adjudicar diferentes conceitos caso estejam disciplinando uma relação privada ou tributária (o que ocorre tão somente pela modificação do contexto, e não em virtude de qualquer supremacia de um ramo sobre o outro).

Contemporânea à discussão sobre a pretensa autonomia do direito tributário, em 1919 foi promulgado o primeiro código tributário do mundo, o Código alemão. Nesse momento foi adotada a teoria da consideração econômica, segundo a qual o fato disciplinado pela norma tributária deveria ser analisado pela substância econômica pretendida pelo indivíduo, devendo ser desconsiderada a forma jurídica utilizada.

Embora a referida teoria não tenha sido adotada pelo Código Tributário Brasileiro, que ingressou no ordenamento jurídico em 1966, o contexto histórico que ainda suscitava debates acerca da vinculação entre o direito tributário e o privado fez com que o legislador pátrio inserisse os artigos 109 e 110 do Código Tributário Nacional.

Por meio do art. 109 do CTN, o legislador transmitiu que, na maior parte das vezes, o direito tributário se serve de conceitos de direito privado para instituir as normas tributárias, atuando como um direito de sobreposição, no sentido de que colhe o conceito da situação tributada em norma de outro ramo do sistema jurídico.

Todavia, é importante destacar que a aludida sobreposição não implica uma necessária submissão aos conceitos de direito privado. Isso porque, como não há qualquer prevalência de um ramo sobre o outro, o direito tributário poderá alterar os conceitos de direito privado de acordo com a finalidade pretendida, 
definindo os efeitos tributários que the convier, conforme preconiza o trecho final do art. 109.

Destaque-se que, como o sistema é uno, caso a norma tributária não defina os contornos do conceito que utilizou, faz-se necessário utilizar-se do conceito preexistente no sistema jurídico, verificando o diálogo entre os textos jurídicos (intertextualidade). Todavia, para que reste incólume a premissa da unidade sistémica, sempre que a norma tributária pretender realizar alguma alteração de conceito, deverá fazê-lo de forma expressa, inovando então no tocante ao conceito preexistente e rompendo nesse ponto o dialogismo.

Mas a norma tributária não possui permissão irrestrita para alterar todos os conceitos de direito privado por ela utilizados. A linha limítrofe dessa pretensão está desenhada no art. 110 do Código Tributário Nacional, determinando que a lei tributária não poderá alterar os conceitos de direito privado que tenham sido utilizados pela Constituição Federal para definir as competências tributárias.

Dessa forma, apenas quando o conceito de direito privado for utilizado na delimitação de competências é que a lei tributária não poderá alterar seu sentido. Em todas as demais hipóteses, não há qualquer vedação.

Isso não implica qualquer supremacia do direito privado em relação ao conceito privado. O dispositivo do art. 110 do CTN demonstra apenas a supremacia da Constituição Federal, advertindo que 0 legislador infraconstitucional não poderá modificar sua competência mediante a alteração dos conceitos ali constantes.

Dado que a Constituição é a pedra angular do ordenamento jurídico, parte da doutrina afirma que o conteúdo do art. 110 do CTN é meramente didático e despiciendo. No entanto, entendemos que a ressalva possui grande valia como uma consignação expressa que busca a segurança jurídica.

Dessa forma, ao se deparar com uma norma constitucional que delimite competência tributária, o intérprete deverá averiguar se a Constituição incorporou algum conceito de direito privado e, caso a resposta seja negativa, deverá 
analisar os diplomas privados vigentes à época de modo a construir o conceito que limitará as alterações por meio da lei tributária.

A interpretação da norma de competência deverá perquirir o sentido possível partindo-se das normas existentes à época de sua promulgação, de modo a privilegiar o princípio da segurança jurídica e evitar que o ente tributário se utilize de subterfúgios interpretativos para ampliar a própria competência tributária que Ihe foi atribuída pela Carta Magna. Desejando-se alterar a competência, faz-se necessária a edição de uma emenda constitucional.

Por fim, testamos nossa hipótese mediante a análise pragmática de conceitos de direito privado cuja modificação foi pretendida por normas de direito privado, demonstrando que, quando o conceito alterado está crivado na Constituição como forma de atribuição de competência (como no caso dos conceitos de serviço, mercadoria, propriedade e faturamento), a alteração pretendida pela lei tributária constitui uma afronta ao art. 110 do Código Tributário Nacional e à Constituição.

De igual modo, demonstramos que, quando se utiliza o conceito de direito privado sem realizar qualquer alteração expressa, o direito tributário atua como legítimo direito de sobreposição, cabendo ao intérprete investigar os limites do conceito privatístico para compreender a extensão da norma tributária.

Sendo assim, não há que se falar em primazia ou submissão do ramo do direito tributário em relação ao direito privado. Ambos constituem uma parte do mesmo sistema jurídico uno e indivisível, porém complexo. Referida complexidade permite que um termo designe um determinado conceito no contexto do direito privado e outro conceito no seio do direito tributário, sendo vedado apenas que a norma tributária altere conceitos utilizados pela Constituição Federal para delimitação da própria competência tributária. 


\section{BIBLIOGRAFIA}

ALCHORRÓN, Carlos; BULYGIN, Eugênio. Sobre la existência de las normas jurídicas. México: Distribuciones Fontamara, 1997.

AMARO, Luciano. Direito Tributário Brasileiro. 15ª ed. São Paulo: Saraiva, 2009.

ANDRADE, José Maria Arruda de. Interpretação da Norma Tributária. São Paulo: MP Editora, 2006.

ARAÚJO, Clarice Von Oertzen. Fato e Evento Tributário - Uma análise Semiótica. In: DE SANTI, E. M. (coord.). Curso de Especialização em Direito Tributário: Estudos analíticos em homenagem a Paulo de Barros Carvalho. Rio de Janeiro: Forense, 2007.

ATALIBA, Geraldo; GIARDINO, Cléber. PIS - Exclusão do ICMS de sua base de cálculo. Revista de Direito Tributário oㅡ 35, 1986, p. 156.

. Sistema Constitucional Tributário Brasileiro. 1를 ed. São Paulo: RT, 1966. ; GIARDINO, Cláber. Núcleo da definição constitucional do ICM. Revista de Direito Tributário. São Paulo, ano VII, no 25-26.

ÁVILA, Humberto. Eficácia do novo Código Civil na legislação tributária. In: GRUPENMACHER, Betina Treiger (coord.). Direito tributário e o novo Código Civil. São Paulo: Quartier Latin, 2004.

BARRETO, Aires Fernandino. Curso de Direito Tributário Municipal. São Paulo: Saraiva, 2009.

. ISS na lei complementar $116 / 03$ e na Constituição. In: TORRES, Heleno Taveira (org.). Inconstitucionalidade dos itens 21 e 21.1 da lista de serviços anexa à LC 116/2003. Barueri-SP: Manole, 2004. 
BARRETO, Paulo Ayres. Ordenamento e sistemas jurídicos. In: CARVALHO, Paulo de Barros (coord.). Construtivismo Lógico Semântico. Vol. I. São Paulo: Noeses, 2014.

. Planejamento tributário: limites normativos. São Paulo: Noeses, 2016.

BECKER, Alfredo Augusto. Teoria Geral do Direito Tributário. 4aㅡ ed. São Paulo: Noeses, 2007.

BEISSE, Heinrich. O critério econômico na interpretação das leis tributárias segundo a mais recente jurisprudência alemã. In: MACHADO, Brandão (coord.) Direito tributário: estudos em homenagem ao Prof. Ruy Barbosa Nogueira. São Paulo: Saraiva, 1984.

BIANCO, João Francisco. O Planejamento Tributário e o Novo Código Civil. In: BORGES, Eduardo de Carvalho (coord.). Impacto Tributário do Novo Código Civil. São Paulo: Quartier Latin, 2004.

BLACK, Max. Definition, Pressuposition, and Assertion. Problems of Analysis. Londres: Routledge, 1954.

BRITTO, Lucas Galvão de. Dividir, definir e classificar: Conhecer é recortar o mundo. In: CARVALHO Paulo de Barros (coord.). Construtivismo Lógico Semântico. Vol. I. São Paulo: Noeses, 2014.

. O Lugar e o Tributo. São Paulo: Noeses, 2014.

CARNEIRO, Luísa Cristina Miranda. IPVA: teoria, prática e questões polêmicas. 1ª ed. São Paulo: Noeses, 2016.

CARRAZZA, Roque Antonio. ICMS. 10ª ed. São Paulo: Malheiros: 2005.

CARVALHO, Aurora Tomazini de. Constructivismo lógico-semântico como método de trabalho na elaboração jurídica. In: CARVALHO, Paulo de Barros Carvalho (coord.). Construtivismo Lógico Semântico. Vol. I. São Paulo: Noeses, 2014.

Curso de Teoria Geral do Direito: o construtivismo lógico-semântico. São Paulo: Noeses, 2009. 
. Tributação sobre receita - Definição do conceito de 'receita' para fins de incidência do IRPJ, CSLL, PIS e COFINS. In: SANTI, Eurico Marcos Diniz de. Tributação e processo. São Paulo: Noeses, 2007.

CARVALHO, Cristiano. Teoria do Sistema Jurídico: direito, economia, tributação. São Paulo: Quartier Latin, 2005.

CARVALHO, Paulo de Barros. A regra matriz do ICM. (Tese de Livre Docência em Direito) - Pontifícia Universidade Católica de São Paulo, São Paulo, 1981.

Algo sobre o constructivismo lógico-semântico. In: CARVALHO, Paulo de Barros Carvalho (coord.). Construtivismo Lógico Semântico. Vol. I. São Paulo: Noeses, 2014.

. Curso de Direito Tributário. 19ª ed. São Paulo: Saraiva, 2007.

. Direito Tributário: Fundamentos Jurídicos da Incidência. $7^{\text {a}}$ ed. São Paulo: Saraiva, 2009.

. Direito Tributário: Linguagem e Método. 2aㅡ. ed. São Paulo: Noeses, 2008.

. Poesia e Direito - O Legislador como poeta: anotações ao pensamento de Flusser. In: HARET, Florence; CARNEIRO, Jerson (coord.). Vilém Flusser e Juristas: comemoração aos 25 anos do grupo de estudos Paulo de Barros Carvalho. São Paulo: Noeses, 2009.

. Teoria da Norma Tributária. 5ª ed. São Paulo: Quartier Latin, 2009.

. O absurdo da interpretação econômica do "fato gerador" - Direito e sua autonomia - O paradoxo da interdisciplinariedade. Revista de Direito Tributário, v. 97, 2007.

CATÃO, Marcos André Vinhas. O método Sistemático. In: TORRES, Ricardo Lobo Torres (coord.). Temas de Interpretação de Direito Tributário. Rio de Janeiro. Renovar, 2003. 
CHACPE, Juliana Fernandes. Do conceito de imóvel rural como unidade de exploração econômica: consequências quanto à forma de elaboração de laudo agronômico de fiscalização e a classificação fundiária do imóvel para fins de desapropriação para reforma agrária. Disponível em $<$ http://www.agu.gov.br/page/download/index/id/7134726>.

CIVITA, Victor. Grande Dicionário LAROUSSE CULTURAL da Língua Portuguesa Nova Cultural 1999. São Paulo: Nova Cultural, 1999.

COÊLHO, Sacha Calmon Navarro. Pis/COFINS - Lei 9.718/98: Entidades fechadas e previdência privada. Revista Dialética de Direito Tributário, no 55, São Paulo: Dialética, 2000.

COPI, Irving M. Introdução à Lógica. São Paulo: Mestre Jou, 1981.

COSTA, Alcides Jorge. Direito Tributário e Direito Privado. In: MACHADO, Brandão (coord.). Direito Tributário: estudos em homenagem ao Prof. Ruy Barbosa Nogueira. São Paulo: Saraiva, 1984.

COSTA, Regina Helena. Curso de Direito Tributário: Constituição e Código Tributário Nacional. São Paulo: Saraiva, 2009.

DINIZ, Marcelo de Lima Castro; PEIXOTO, Marcelo Magalhães. Reflexos do novo Código Civil no Direito Tributário. In: GRUPPENMACHER, Betina Treiger (coord.). Direito tributário e o novo Código Civil. São Paulo: Quartier Latin, 2004.

. Curso de direito civil brasileiro. Vol. 4: Direito das Coisas. $27^{a}$ ed. São Paulo: Saraiva, 2012.

FACHIN. Luiz Edson. Considerações sobre o ITBI Inter Vivos e o Regime Contemporâneo das Titularidades e do Trânsito Jurídico à Luz do Novo Código Civil Brasileiro. In: GRUPPENMACHER, Betina Treiger (coord.). Direito tributário e o novo Código Civil. São Paulo: Quartier Latin, 2004.

FALCÃO, Amílcar de Araújo. Fato gerador da obrigação tributária. 6ª ed. Rio de Janeiro: Forense, 1999. 
FARIAS, Cristiano Chaves de; ROSENVALD, Nelson. Direitos Reais. $2^{\underline{a}}$ ed. Rio de Janeiro: Lumen Juris, 2006.

FERRAZ JÚNIOR, Tércio Sampaio. Conceito de sistema no direito. São Paulo: 1976.

Introdução ao Estudo do Direito: Técnica, Decisão, Dominação. 7ª ed. São Paulo: Atlas, 2013.

FERREIRA, Aurélio Buarque de Holanda. Novo Dicionário da Língua Portuguesa. Nova Fronteira, 1986.

FIORIN, José Luiz. Interdiscursividade e intertextualidade. In: BRAIT, Beth (org.). Bakhtin outros conceitos-chave. São Paulo: Contexto, 2010.

FLUSSER, Vilém. Língua e Realidade. São Paulo: Annablume, 2007.

FRANÇA, Rubens Limongi. Hermenêutica jurídica. São Paulo: Saraiva, 1997.

GAGLIANO, Pablo Stolze; FILHO, Rodolfo Palplona. Novo curso de direito civil: (abrangendo o Código de 1916 e o novo Código Civil). São Paulo: Saraiva, 2003.

GENY, François. O particularismo do direito fiscal. Revista de Direito Administrativo, vol. 20, 1950.

GODOI, Marciano Seabra de; SALIBA, Luciana Goulart Ferreira. Interpretação e aplicação da lei tributária. In: MACHADO, Hugo de Britto (coord.). São Paulo: Dialética; Fortaleza: Instituto Cearense de Estudos Tributários - ICET, 2010.

GONÇALVES, Carlos Alberto. Direito Civil Brasileiro. Vol. 3. Contratos e Atos Unilaterais. 12 $2^{\mathrm{a}}$ ed. São Paulo: Saraiva, 2015.

. Direito civil brasileiro. Vol. 2. Teoria Geral das Obrigações. 9ª ed. São Paulo: Saraiva, 2012.

GRAU, Eros Roberto. Direito, conceitos e normas jurídicas. São Paulo: Revista dos Tribunais, 1988. 
GUASTINI, Riccardo. Das fontes às normas. Trad. Edson Bini. São Paulo: Quartier Latin, 2005.

GUIBOURG, Ricardo; GHIGLIANI, Alejandro; GUARINONI, Ricardo. Introduccion al conocimiento científico. Buenos Aires: EUDEBA.

HARTZ, Wilhelm. Interpretação da lei tributária. Trad. Brandão Machado. São Paulo: Resenha Tributária, 1993.

HOFFMANN, Susy Gomes. O Imposto sobre Serviços de Qualquer Natureza. In: DE SANTI, E. M. (coord.). Curso de Especialização em Direito Tributário: Estudos analíticos em homenagem a Paulo de Barros Carvalho. Rio de Janeiro: Forense, 2007.

HOUAISS, Antonio; VILLAR, Mauro de Salles. Dicionário Houaiss de Língua Portuguesa. 2 $2^{\mathrm{a}}$ Reimpressão com alterações. Rio de Janeiro: Objetiva, 2001.

HUCK, Hermes Marcelo. Elisão e evasão: rotas nacionais e internacionais do planejamento tributário. Tese de Titularidade, Departamento de Direito Econômico e Financeiro da Faculdade de Direito da USP. São Paulo, 1996.

JÚNIOR, Goffredo Telles. O direito quântico. 6aㅗ ed. São Paulo: Max Limonad, 1985.

KELSEN, Hans. Teoria pura do direito. $8^{\mathrm{a}}$ ed. Trad. João Batista Machado. São Paulo: Martins Fontes, 2009.

. Teoria Geral do direito e do estado. Trad. por Luis Carlos Borges. São Paulo: Martins Fontes, 1990.

LARENZ, Karl. Metodologia da ciência do direito. Trad. por José Lamego. Lisboa: Fundação Calouste Gulbenkian, 1997.

LEHNER, Moris. Consideração econômica e tributação conforme a capacidade contributiva. Sobre a possibilidade de uma interpretação teleológica de normas com finalidades arrecadatórias. In: SCHOUERI, Luis Eduardo; ZILVETI, Fernando Aurélio (coords.). Direito Tributário. Estudos em homenagem a Brandão Machado. São Paulo: Dialética, 1998. 
LINS, Robson Maia. A mora no direito tributário. Tese de doutorado apresentada na Pontifícia Universidade Católica de São Paulo em 2008.

. Considerações sobre o conceito de norma jurídica e a pragmática da comunicação na decisão judicial na jurisprudência do Supremo Tribunal Federal. In: CARVALHO, Paulo de Barros Carvalho (coord.). Construtivismo Lógico Semântico. Vol. I. São Paulo: Noeses, 2014.

MACHADO, Brandão (coord.). Direito tributário: estudos em homenagem ao Prof. Ruy Barbosa Nogueira. São Paulo: Saraiva, 1984.

MACHADO, Hugo de Brito. Cofins: Ampliação da base de cálculo e compensação do aumento da alíquota. In: ROCHA, Valdir de Oliveira (coord.). Contribuições sociais - problemas jurídicos (Cofins, PIS, CSLL e CPMF). São Paulo: Dialética, 1999.

. Curso de Direito Tributário. 28ª ed. São Paulo: Malheiros, 2007.

- Interpretação e Integração da Lei Tributária. In: MACHADO, Hugo de Britto (coord.). Interpretação e aplicação da lei tributária. São Paulo: Dialética; Fortaleza: Instituto Cearense de Estudos Tributários - ICET, 2010.

MAXIMILIANO, Carlos. Hermenêutica e Aplicação do Direito. $20^{\mathrm{a}}$ ed. Rio de Janeiro: Forense, 2013.

MELLO, Gustavo Miguez de. Interpretação e Aplicação da Lei Tributária. In: MACHADO, Hugo de Britto (coord.). Interpretação e aplicação da lei tributária. São Paulo: Dialética; Fortaleza: Instituto Cearense de Estudos Tributários - ICET, 2010.

MELLO, Marcos Bernardes de. Teoria do fato jurídico: Plano da existência. $12^{\underline{a}}$ ed. São Paulo: Saraiva, 2003.

MENDES, Sônia Maria Broglia. A validade Jurídica: pré e Pós Giro Linguístico. São Paulo: Noeses, 2007.

MENNE, Alberto. Introducción a la lógica. Madrid: Editorial Gredos, 1969. 
MONTEIRO, Washington de Barros. Curso de direito civil: direito das obrigações. 15a ed. São Paulo: Saraiva, 1979. V. 4 (parte I).

MORCHÓN, Gregorio Robles. Teoria del derecho (fundamentos de teoria comunicacional del derecho). vol. 2. $2^{\mathrm{a}}$ ed. Thomson Civitas, 2006.

MOTARI, Cezar. Introdução à Lógica. São Paulo: UNESP, 2001.

MOUSSALEM, Tárek Moysés. Fontes no direito tributário. $2^{\mathrm{a}}$ ed. São Paulo: Noeses, 2006.

NETTO, Domingos Franciulli. COFINS - A exclusão das receitas financeiras de sua base de cálculo. PIS - COFINS - Questões Atuais e Polêmicas. São Paulo: Quartier Latin, 2005.

NEVES, Marcelo. Teoria da inconstitucionalidade das leis. Saraiva, 1988.

NOGUEIRA, Ruy Barbosa. Curso de Direito Tributário. 10ª ed. São Paulo: Saraiva, 1990.

OLIVEIRA, Ricardo Mariz de. Reflexos do novo código civil no direito tributário. In: BORGES, Eduardo Carvalho (coord.). Impacto Tributário do Novo Código Civil. São Paulo: Quartier Latin, 2004.

Fundamentos do Imposto de Renda. São Paulo: Quartier Latin, 2008.

OPITZ, Osvaldo; OPITZ, Silvia C. B. 1914 - 1982 Tratado de direito agrário brasileiro. São Paulo: Saraiva, 1983.

PEREIRA, Caio Mario da Silva. Instituições de Direito Civil. V. III. Rio de Janeiro: Forense, 2007. . Instituições de Direito Civil. Vol. IV. $19^{a}$ ed. Rio de Janeiro: Forense, 2007.

PISCITELLI, Tathiane dos Santos. Os conceitos de Direito Privado como limites à interpretação de normas tributárias: Análise a partir dos conceitos de faturamento 
e receita. Direito tributário e os conceitos de direito privado. São Paulo: Noeses: IBET, 2010.

. Os limites à interpretação das normas tributárias. São Paulo: Quartier Latin, 2007.

PONTES DE MIRANDA. Direito das coisas: propriedade, aquisição da propriedade imobiliária; atualizado por Luiz Edson Fachin. São Paulo: Editora Revista dos Tribunais, 2012.

REZENDE, Condorcet. A Competência Tributária e o Novo Código Civil. Impacto Tributário do Novo Código Civil. São Paulo: Quartier Latin e IPT, 2004.

SANTI, Eurico Marcos Diniz de. Norma, Evento, Fato, Relação Jurídica, Fontes e Validade no Direito. In: DE SANTI, E. M. (coord.). Curso de Especialização em Direito Tributário: Estudos analíticos em homenagem a Paulo de Barros Carvalho. Rio de Janeiro: Forense, 2007.

SCHOUERI, Luís Eduardo. Direito Tributário. 3르 ed. São Paulo: Saraiva, 2013.

SILVA, De Plácido. Vocabulário Jurídico Forense. Rio de Janeiro: Forense, 1986. . Vocabulário Jurídico. Rio de Janeiro: Forense, 1993. 4v.

SILVA, Leonardo Mussi da; WANDERLEY, Thiago Barbosa. O Direito aos Créditos de PIS e COFINS sobre as Despesas com Arrendamento Rural (art. 3ํㅡ, IV das leis 10.637/02 e 10.833/03) - Reflexos Tributários de um Conceito Civil. In: BORGES, Eduardo (coord.). PIS/COFINS - Apropriação de Créditos - Conceito de Insumos - Posicionamentos do CARF. Quartier Latin, 2014.

SOUSA, Rubens Gomes de. Compêndio de legislação tributária. 2ª ed. Rio de Janeiro: Edições Financeiras, 1965.

Normas de interpretação no Código Tributário Nacional. Interpretação no direito tributário. São Paulo: Saraiva, 1975. 
SOUZA, Priscila de. Intertextualidade na linguagem jurídica: conceito, definição e aplicação. In: CARVALHO, Paulo de Barros (coord.). Construtivismo Lógico Semântico. Vol. I. São Paulo: Noeses, 2014.

TOMÉ, Fabiana Del Padre. A prova no Direito Tributário. 2ª Ede. São Paulo: Noeses, 2008.

. Vilém Flusser e o Construtivismo Lógico-Semântico. In: HARET, Florence; CARNEIRO, Jerson (coord.). Vilém Flusser e Juristas: comemoração aos 25 anos do grupo de estudos Paulo de Barros Carvalho. São Paulo: Noeses, 2009.

TORRES, Heleno. Direito Tributário e Direito Privado - autonomia privada, simulação e elusão tributária. São Paulo: Revista dos Tribunais, 2003.

TROTABAS, Louis. A interpretação das leis fiscais. Revista de Direito Administrativo, vol. 01, 1945.

. Ensaio sobre o Direito Fiscal. Revista de Direito Administrativo, vol. 26, 1951.

VANONI, Ezio. Natureza e interpretação das leis tributárias. Trad. de Rubens Gomes de Souza. Editora Edições Financeiras, 1932.

VELLOSO, Andrei Pitten. Conceitos e competências tributárias. São Paulo: Dialética, 2005.

VENOSA, Sílvio de Salvo. Direito Civil: contratos em espécie. 10ª ed. São Paulo: Atlas, 2010.

. Direito Civil: direitos reais. 10ª ed. São Paulo: Atlas, 2010.

VILANOVA, Lourival. As estruturas lógicas e o sistema de Direito Positivo. 4르 ed. São Paulo: Noeses, 2010.

. Escritos Jurídicos e Filosóficos. vol. 1. São Paulo: AXIS MVNDI e IBET, 2003. 
Lógica Jurídica. São Paulo: Bushatsky, 1976.

Sobre o conceito do direito. Imprensa Oficial: Recife, 1947.

WITTGENSTEIN, Ludwig. Tractatus logico-philosophicus. São Paulo: Edusp, 1994.

XAVIER, Alberto. Tipicidade da Tributação, Simulação e Norma Antielisiva. São Paulo: Dialética, 2001. 